\title{
Analysis of variables related to fatal outcomes of scorpion envenomation in children and adolescents in the state of Minas Gerais, Brazil, from 2001 to 2005
}

\author{
Cláudia M. N. Guerra, ${ }^{1}$ Luís F. A. Carvalho, ${ }^{1}$ Enrico A. Colosimo, ${ }^{2}$ \\ Heliane B. M. Freire ${ }^{3}$
}

\begin{abstract}
Objectives: To describe and evaluate notified scorpion envenomation incidents in children and adolescents in the Brazilian state of Minas Gerais between 2001 and 2005, and to calculate the incidence and mortality and identify factors related to fatal outcomes.

Methods: Analysis of 14,406 mandatory notifications of scorpion envenomation involving patients aged 0 to 19 years in Minas Gerais. After performing a univariate analysis of factors related to mortality $(p<0.25)$, multivariate analysis was carried out using logistic regression.

Results: The number of notifications of accidents involving scorpions increased over the period. The age group that suffered most accidents was 5 to 9 years. Local pain was reported in $95 \%$ of cases. The majority of cases were classified as mild (60\%) and antivenom was given to $42 \%$ of this population. The mean mortality rate was $0.7 \%$. The state capital, Belo Horizonte, was the municipality with the greatest occurrence of incidents. Each hour's delay before receiving first medical care was associated with a $9 \%$ increase in the odds ratio for the likelihood of death, which was 46 times greater in the severe group than in the moderate and mild groups. A decrease of 1 year in patient age was associated with a $13 \%$ increase in the odds ratio for the likelihood of death.
\end{abstract}

Conclusions: There was an increase in the number of notifications over the period studied. The following factors were identified as linked with a higher odds ratio for the likelihood of death: delayed first medical care, being classified as a severe case, and younger age of victim. child.

J Pediatr (Rio J). 2008;84(6):509-515: Scorpion envenomation, envenomation, epidemiology, scorpion bite, adolescent,

\section{Introduction}

Scorpion stings are a public health problem in some of the states in Brazil, with large numbers of cases notified each year, traditionally in the states of Minas Gerais and São Paulo. ${ }^{1-3}$ Scorpion envenomation still causes deaths in Brazil, despite the availability of antivenom and advances in critical care medicine, which plays an important role in severe cases.

The majority of stings occur during hot rainy months, ${ }^{2-4}$ have a benign course and a lethality of $0.58 \%$. Deaths have been linked to an increased frequency of children ${ }^{2}$ under 14 years of age being stung by Tityus serrulatus. ${ }^{1}$

Scorpions are carnivorous animals that primarily feed on insects. ${ }^{5}$ They have nocturnal habits and spend the day hidden in dark and humid places, ${ }^{1,2}$ and can be encountered inside houses, in domestic rubbish, behind skirting and in cellars and attics. ${ }^{5}$ They can enter residences via the sewage system. ${ }^{6}$ Tityus serrulatus lives for 3 to 5 years and can survive

1. Mestre, Faculdade de Medicina, Universidade Federal de Minas Gerais (UFMG), Belo Horizonte, MG, Brazil.

2. Pós-doutor. Professor adjunto, Departamento de Estatística, Instituto de Ciências Exatas, UFMG, Belo Horizonte, MG, Brazil.

3. Doutora. Professora associada, Departamento de Pediatria, UFMG, Belo Horizonte, MG, Brazil.

No conflicts of interest declared concerning the publication of this article.

Suggested citation: Guerra CM, Carvalho LF, Colosimo EA, Freire HB. Analysis of variables related to fatal outcomes of scorpion envenomation in children and adolescents in the state of Minas Gerais, Brazil, from 2001 to 2005. J Pediatr (Rio J). 2008;84(6):509-515.

Manuscript received May 26 2008, accepted for publication Aug 032008.

doi:10.2223/JPED.1847 
for many months without food or water. It reproduces by parthenogenesis. ${ }^{3,6}$ These characteristics have made it very difficult to combat, since they make dispersal of the species more likely.

The venom causes adrenergic and/or cholinergic substances to be released. ${ }^{7,8}$ Recent studies have detected high levels of cytokines in circulation, which may participate in the genesis of the changes caused by scorpion envenomation. ${ }^{9}$ Patients are generally agitated with localized pain, sialorrhea, diaphoresis and vomiting, and may become torpid or comatose. They may present conditions ranging from mild tachypnea to acute pulmonary edema (APE). ${ }^{10}$ There will often be tachycardia. Occasionally, arrhythmia and transitory systemic arterial hypertension, ${ }^{11}$ arterial hypotension and even circulatory shock, which is generally cardiogenic, will also be observed. $7,8,11$

The Brazilian Ministry of Health published a manual in $2001^{1}$ that includes a clinical classification of scorpion stings as: mild, when there is localized pain and paresthesia; moderate, when there is discrete sialorrhea, diaphoresis vomiting and nausea and agitation, tachypnea and tachycardia; or severe, when, in addition to the above, one or more of the following: profuse and uncontrollable vomiting, profuse diaphoresis, intense sialorrhea, prostration, convulsions, coma, bradycardia, heart failure, pulmonary edema and/or shock.

Diagnosis is based on clinical history of a sting or sudden illness, particularly in endemic areas, combined with recognition of symptomology and laboratory test results suggestive of scorpion envenomation: hyperglycemia, hyperamylasemia and elevated creatine phosphokinase which is increased by rhabdomyolysis ${ }^{12}$ and its cardiac fraction. ${ }^{1,13}$ Further tests are generally needed: hemagram, ${ }^{13}$ arterial blood gas analysis, ${ }^{13,14}$ chest X-ray, ${ }^{13}$ electrocardiogram ${ }^{9-18}$ and echocardiogram. ${ }^{9,13}$ To confirm diagnosis, the venom in circulation can be assayed using ELISA (enzyme-linked immunosorbent assay), although this is not yet available for clinical practice. ${ }^{1,13}$

Treatment in mild cases basically consists of pain management. ${ }^{1,13}$ For moderate and severe cases and where the victim is a child less than 3 years old, scorpion antivenom is indicated, administering two to three ampoules in moderate cases and four to six in severe cases. The antivenom is given intravenously, as quickly as possible, in order to neutralize venom in the circulation. ${ }^{1,19}$

The objectives of this study were: to describe and analyze the notifications of scorpion stings suffered by children and adolescents in the state of Minas Gerais between 2001 and 2005; to calculate their incidence and lethality; and to identify factors related with fatal outcomes.

\section{Methods}

All notifications of scorpion envenomation of children and adolescents (from 0 to 19 years) occurring in the state of
Minas Gerais from 2001 to 2005 and entered on the database of the Information System for Notifiable Diseases (Sinan Sistema de Informação de Agravos de Notificação) were analyzed. A total of 201 cases were excluded because the neither the ages nor dates of birth of the patients were known.

The National Program for the Control of Accidents with Poisonous Animals (Programa Nacional de Controle de Acidentes por Animais Peçonhentos) has existed since 1988 and Sinan was made a part of it when compulsory notification of scorpion envenomation was introduced in Brazil. The objective of the program is to improve the management of accidents caused by poisonous animals. In 1998 the health service was computerized and Sinan was put into operation. Since that date the system has been improved and an increasing number of notifications have been received. From the year 2000 onwards there was an impressive increase in the number of notifications.

Sinan provides a standard unified notification form for all poisonous animals. This study analyzed only those data relating to scorpion envenomation. All variables on the form are collected categorically: (1) yes, (2) no and (9) unknown. The form offers the following scorpion species options: Tityus serrulatus, Tityus bahiensis, Tityus stigmurus, Bothriurus, other species and species unknown. There is also a severity classification based on the patient's clinical presentation according to the criteria in the 2001 Manual published by the Brazilian Ministry of Health. ${ }^{1}$

Epi-Info (version 6.04) was used to analyze data that had been tabulated on TabWin. Proportions were compared using the chi-square test or the Fisher test when the expected value of the cell was less than five. Odds ratios and their respective $95 \%$ confidence intervals were calculated. Factors that univariate analysis indicated had a relationship with mortality at $p<0.25$ were selected for multivariate analysis by logistic regression, carried out using the Statistical Package for the Social Sciences (SPSS). In the final model, $\mathrm{p}<0.05$ was defined as the cut-off point for statistical significance. This project was approved by the Research Ethics Committee at the Universidade Federal de Minas Gerais (UFMG) under protocol number ETIC 037/06.

\section{Results}

A total of 14,406 incidents involving children and adolescents aged up to 19 years notified in the state of Minas Gerais from 2001 to 2005 were studied. There was a progressive increase in the number of notifications from year to year $(2,116,2,656,2,776,3,182$, and 3,676, respectively) and male victims predominated, with $55 \%$ of cases. The greatest number of envenomations occurred during hot and humid months, with the majority during September, October, November and December. 
Table 1 - Percentages of children and adolescents presenting with clinical signs at health centers after scorpion stings (Minas Gerais, Brazil, 2001-2005)

\begin{tabular}{lccc}
\hline Systemic & At location of sting & Myotoxic & Location of injury \\
\hline $27 \%$ vomiting & $95 \%$ pain & $12 \%$ myalgia & $46 \%$ UL \\
$6 \%$ respiratory failure & $30 \%$ edema & $1 \%$ oliguria & $37 \%$ LL \\
$3 \%$ hypotension & $24 \%$ erythema & $0.4 \%$ renal insufficiency & $3 \%$ head \\
$2 \%$ APE & $3 \%$ ecchymosis & $0.8 \%$ dark urine & $8 \%$ location unknown \\
$2 \%$ shock & - & $0.5 \%$ anuria & - \\
$1 \%$ diarrhea & - & & - \\
\hline
\end{tabular}

$\mathrm{APE}=$ acute pulmonary edema; $\mathrm{LL}=$ lower limbs; $\mathrm{UL}=$ upper limbs.

In $40 \%$ of the sample it was possible to identify the species; $87 \%$ of these patients had been stung by Tityus serrulatus. No correlation was detected between scorpion species and severity of clinical status. Of those cases where the place that the accident occurred was recorded, 7,797 (57\%) were in urban areas and 5,910 (43\%) were in rural areas. The odds ratio that a patient stung in a rural area would die was 2.48 times greater than when the accident occurred in an urban area $(p<0.001)$.

The age group that suffered most accidents was 5 to 9 years, with 4,217 cases (29\%); the age group least affected was less than 1 year old, with 405 cases (3\%). There were 2,912 cases ( $20 \%$ ) in the 1 to 4 years age group; 3,624 cases $(25 \%)$ in 10 to 14 -year-olds; and 3,248 cases (23\%) in the 15 to 19 years group, $(p<0.001)$.

With relation to the clinical manifestations, $95 \%$ of the patients described pain on admission and $27 \%$ suffered vomiting (Table 1).

With relation to severity of the cases, $60 \%$ were considered mild, $23 \%$ moderate and $7 \%$ severe, while $10 \%$ were of unknown severity. The majority of severe cases (77\%) were children less than 9 years old. The younger the age the more severe the event $(p<0.001)$.

A linear relationship was identified between case severity classification and the frequency of death, i.e., the more severe the case classification, the greater the number of deaths. The severe cases had an odds ratio for the likelihood of death that was 820.47 times than the mild cases (Table 2).

In addition to the increase in the number of cases notified over the years, there was also an increase in the number of ampoules of scorpion antivenom used each year: 4,814, $5,388,5,699,6,043$ and 6,728, respectively. Lethality varies $(0.5$ to $1.0 \%)$ over the years analyzed, with a mean of $0.7 \%$ for the 5-year period. The variation in the number of deaths over these years was not significant $(p=0.05)$.

The greater the period elapsed between the sting and first medical care, the greater the number of deaths. It was observed that among those seen between 6 and 12 hours after the sting, death occurred 8.77 times more often in comparison with those seen during the first hour $(p=0.003)$.

Lethality varied according to age group, being greatest among patients aged 1 to 4 years. The odds ratio for the likelihood of death among these cases was 24.36 times greater than for patients aged 15 to 19 years (Table 3 ).

Of the 14,406 cases of scorpion envenomation, 8,254 $(57 \%)$ were given specific antivenom. Among the mild cases, $42 \%$ (3,613 patients) were given antivenom, while $92 \%$ $(3,099)$ of the moderate and $95 \%(930)$ of the severe cases received antivenom. A total of 28,672 ampoules were used, 10,950 given to patients with mild scorpion envenomation, 10,821 to moderate patients and 4,353 to severe cases ( $p<$ $0.0001) ; 2,548$ ampoules were used in cases whose severity was ignored. In 8,013 notifications the number of ampoules administered was provided; a total of 27,496 were administered in these cases; with a mean of 3.43 ampoules and a standard deviation of 1.39 ( 1 to 15 ampoules), median of 4 ampoules and interquartile range $25-75 \%$ (IQ25-75\%) of 2-4 ampoules. The lower the age of the patient the greater the use of specific antivenom ( $p=0.001)$.

A univariate analysis was performed for each of the symptoms on admission with relation to the chance of death, and several factors were identified with statistical significance ( $p$ $<0.25$ ): diarrhea, vomiting, APE, hypotension, respiratory failure, oliguria, myalgia, living in a rural area, time between sting and first medical care, young patients and case severity. 
Table 2 - Distribution of deaths according to severity of cases of children and adolescents who had been victims of scorpion envenomation (Minas Gerais, 2001-2005) $(n=12,858)$

\begin{tabular}{|c|c|c|c|c|}
\hline \multirow[b]{2}{*}{ Severity classification } & \multicolumn{2}{|c|}{ Death } & \multirow[b]{2}{*}{ Total } & \multirow[b]{2}{*}{ OR (95\%CI) } \\
\hline & Yes (\%) & No $(\%)$ & & \\
\hline Mild & $1(0.001)$ & $8,258(99.99)$ & 8,259 & 1 \\
\hline Moderate & $6(0.19)$ & $3,178(99.80)$ & 3,184 & $15.59(1.88-343.77)$ \\
\hline Severe & $77(9.00)$ & $775(91.00)$ & 852 & $820.47(123.73-15,918)$ \\
\hline Unknown & $4(0.70)$ & $559(99.30)$ & 563 & - \\
\hline Total & $88(0.70)$ & $12,770(99.30)$ & 12,858 & - \\
\hline
\end{tabular}

$95 \%$ CI $=95 \%$ confidence interval; OR = odds ratio.

$\mathrm{p}=0.001$.

Chi-square test for linear tendencies $=285.99$.

Table 3 - Distribution of deaths according to age of children and adolescents who were victims of scorpion envenomation in Minas Gerais between 2001 and $2005(n=12,852)$

\begin{tabular}{|c|c|c|c|c|}
\hline \multirow[b]{2}{*}{ Age group } & \multicolumn{2}{|c|}{ Death (lethality) } & \multirow[b]{2}{*}{ Total } & \multirow[b]{2}{*}{ OR (95\%CI) } \\
\hline & Yes (\%) & No $(\%)$ & & \\
\hline$<1$ year & $3(0.9)$ & $345(99.1)$ & 348 & $12.55(1.71-107.34)$ \\
\hline $1-4$ years & $43(1.7)$ & $2,747(98.3)$ & 2,590 & $24.36(5.78-145.46)$ \\
\hline $5-9$ years & $27(0.7)$ & $3,773(99.3)$ & 3,800 & $10.33(2.89-62.83)$ \\
\hline $10-14$ years & $13(0.4)$ & $3,219(99.6)$ & 3,232 & $5.83(1.26-37.38)$ \\
\hline $15-19$ years & $2(0.1)$ & $2,886(99.9)$ & 2,888 & 1 \\
\hline Total & $88(0.7)$ & $12,770(99.3)$ & 12,858 & - \\
\hline
\end{tabular}

$95 \% \mathrm{CI}=95 \%$ confidence interval; OR = odds ratio.

$\mathrm{p}=0.001$.

Chi-square test for linear tendencies $=45.929$.

The multivariate analysis identified five factors that were significantly related to increased mortality from a statistical perspective (Table 4).

Each extra hour's delay before first medical care increased the odds ratio for the likelihood of death by $9 \%$. The odds ratio for the likelihood of death for the severe subset was 46 times greater than for the mild and moderate subset. The odds ratio for the likelihood of death among hypotense patients was 2.7 times greater than for patients without hypotension on admission. The odds ratio for the likelihood of death increased by
$13 \%$ for each year by which patient age reduced. The odds ratio for death for patients with respiratory failure on admission was 6 times greater than for patients without this symptom.

The municipality with the greatest occurrence of scorpion envenomation incidents was Belo Horizonte, followed by Governador Valadares and then Montes Claros. The greatest incidence was in Conceição das Alagoas (629/100,000 inhabitants); the greatest mortality in Pavão (0.1310/1,000 inhabitants); and the greatest lethality was in the municipality of Santa Luzia (14.29\%). 
Table 4 - Factors related to increased mortality in a multivariate analysis of scorpion envenomation of children and adolescents in Minas Gerais from 2001 to 2005

\begin{tabular}{lcc}
\hline Risk factors & $\mathbf{p}$ & OR (95\% CI) \\
\hline Time before first medical care & 0.043 & $1.09(1.00-1.19)$ \\
Severity (mild/moderate vs. severe) & 0.000 & $45.76(15.20-137.8)$ \\
Hypotension & 0.009 & $2.63(1.28-5.55)$ \\
Age & 0.004 & $1.13(1.04-1.23)$ \\
Respiratory failure & 0.000 & $6.25(3.22-12.5)$ \\
\hline
\end{tabular}

$95 \% \mathrm{CI}=95 \%$ confidence interval; OR = odds ratio.

\section{Discussion}

The progressive increase in notifications that was detected by this study may be the result of a more efficient system, but it could also be due to an increasing number of incidents.

In Brazil, Tityus serrulatus is considered an opportunistic scorpion species, i.e. it survive natural selection by having greater ecological plasticity and because it multiplies rapidly. This explains its wide distribution across areas of Southeast Brazil and part of Bolivia, via the state of Rondônia, ${ }^{20}$ which had not been described before.

The greatest number of incidents occurred in the state capital Belo Horizonte. This city was built on scorpion-infested land, ${ }^{3,11}$ with quarries, ravines, marble mines and old buildings. The scorpions are constantly being evicted from their natural habitat by the city's growth. Living side-by-side with the human population means that the risk of incident is very high. 3,4

With relation to the predominance of cases in hot and humid months, there is a report that scorpions are more active during these periods, primarily as a result of reproduction. ${ }^{4}$

There was no correlation that had significance from a statistical perspective between the species of scorpion identified and the severity of the clinical case. This is probably due to the small percentage of cases in which the species were identified $(40 \%)$, with predominance of Tityus serrulatus in $87 \%$ of identified cases, and also due to the small number of "other species" (13\%).

The age group least affected was $<1$ year, which agrees with a study carried out in Belo Horizonte between 1990 and 1997. ${ }^{3}$ In that study, children less than 1 year old accounted for $0.1 \%$ of the study population, which is because exposure to high-risk places is necessary for incidents to occur. At this age, children are more restricted to their cots and pushchairs or are being held or are on the floor of the residence.
There is consensus that scorpions do not only attack and sting when they feel threatened, which explains the high number of stings to upper limbs (46\%) while handling dangerous material, which turns out to house or hide scorpions, generally dark and humid places. ${ }^{2}$

The majority of the severe cases (77\%) affected children under 9 years old, which is attributable to the higher proportion of venom injected with relation to body surface area, resulting in higher concentrations in serum. ${ }^{21}$ According to Rezende et al., the severity of a scorpion sting is related to the concentration of the venom in plasma. ${ }^{22}$

It is known that several factors have an effect on lethality in different regions and countries (lethality is $7.6 \%$ in Tuni$\mathrm{sia}^{23}$ and $23 \%$ in Nigeria), ${ }^{24}$ primarily the type of scorpion and the availability of species-specific antivenom. The mean lethality found here was $0.7 \%$, which is discretely elevated when compared with data from the general populations of Minas Gerais, Bahia and São Paulo states held on Sinan for 2001 to $2005: 0.24,0.32$ and $0.06 \%$, respectively. This is the result of exclusively analyzing the pediatric age group. Although the increase in lethality described in the literature for the extremes of age was not observed, children less than 1 year old did have an odds ratio for the probability of death that was 12.55 times greater than the adolescents aged 15 to 19 years.

The unfavorable outcomes among patients who arrived at admission in a severe condition is the result, among other causes, of the higher serum concentration of the venom and increased bonding to its areas of activity, already having initiated pathological changes. The increased length of time before first medical care (antivenom) allows more and more venom to bind to its sites of activity, which can worsen prognosis, since the antivenom neutralizes venom in circulation. The need to administer antivenom early to increase efficacy is therefore emphasized. 
The majority of Brazilian and international authors use antivenom therapy and accept its efficacy. In contrast, Gueron, from Israel, is the most enthusiastic author who claims they are ineffective. ${ }^{25}$ In this wide-ranging discussion, certain factors should be taken into consideration. It is known that in order to achieve the greatest efficacy from antivenom, it should be species-specific, well-conserved, administered as early as possible ${ }^{1,13}$ and at a dosage that is sufficient to neutralize all of the venom in circulation. ${ }^{22}$ Generally, to guarantee fast neutralization of the venom, antivenom will be given intravenously, ${ }^{26}$ rapidly and with no premedication to avert supposed reactions to it. ${ }^{1,13}$

In a study carried out at a center of excellence in Israel, Bentur et al. ${ }^{27}$ stated that the different species associated with the majority of mild cases (primarily in the north and central regions of Israel) and the rapid absorption of the venom from the species responsible for the greatest severity (Leiurus quinquestriatus) explained the lack of efficacy of antivenom in that country and was why it is not used there.

This study has emphasized the importance of using scorpion antivenom in Brazil, since delays in administering it were directly correlated with increased numbers of deaths.

Many of the patients with mild scorpion envenomation among the cases studied for this analysis were given scorpion antivenom, which suggests this treatment is being abused. It could also suggest that cases are being incorrectly classified in terms of severity or that patients arrived with mild symptoms on admission and progressed to more dangerous forms, changing classification, and therefore requiring antivenom therapy.

The use of antivenom in mild cases may imply unnecessary risks and expenses for patients and institutions. Of the 28,672 ampoules used during the period studied, 10,959 were used for mild cases, greatly increasing treatment costs. The current cost of each ampoule is $R \$ 21.24$, and so $R \$$ $232,769.16$ was spent on mild cases.

Sixteen patients with severe cases were not given specific antivenom. This raises the suspicion that the treating professional lacked knowledge, that there was no antivenom at the treatment center or that severity was classified incorrectly on admission.

Incidence rates were much higher in small municipalities, which, although the absolute number of cases was smaller, indicates a high risk for such small populations. Since incidence is a relative population index, it allows better comparisons between populations, reflecting differences in health (socioeconomic) status between towns.

Lethality was inversely proportional to the total number of cases. In Belo Horizonte, lethality was $0.16 \%$, while in Montes Claros, which had the third highest number of incidents, there were no deaths from scorpion envenomation during the period. It is known that, in areas with a greater incidence, in addition to appropriate infrastructure and trained services, the population themselves are also aware of the severity of incidents and the urgent need for medical treatment. In small municipalities, in addition to possible transportation delays, there may also be a lack of preparation to deal with isolated cases, influencing prognosis.

Despite the large sample and the fact that it covers 5 years, this study is limited by being based on retrospective analysis of a database populated from varying sources (different health professionals), some incomplete. There is also the possibility of typing errors and of under notification in certain regions.

\section{Conclusions}

The results of this study have revealed an increase in the number of notified cases of scorpion envenomation in the state of Minas Gerais over the five-year period. Incidents predominantly affected males, occurred during hot and rainy months and were generally secondary to stings by Tityus serrulatus. The observed lethality was low, but increased time between being stung and first medical care, younger age of victims and cases classified as severe were all factors related to death.

\section{References}

1. Brasil. Ministério da Saúde. Manual de diagnóstico e tratamento de acidentes por animais peçonhentos. $2^{\mathrm{a} e d}$. Brasília, DF: Fundação Nacional de Saúde; 2001.

2. Ribeiro LA, Rodrigues L, Jorge MT. Aspectos clínicos e epidemiológicos do envenenamento por escorpiões em São Paulo e municípios próximos. Rev Patol Trop. 2001;30:83-92.

3. Soares MR, de Azevedo CS, De Maria M. Escorpionismo em Belo Horizonte, MG: um estudo retrospectivo. Rev Soc Bras Med Trop. 2002;35:359-63.

4. Nunes CS, Bevilacqua PD, Jardim CC. Aspectos demográficos e espaciais dos acidentes escorpiônicos no Distrito Sanitário Noroeste, Município de Belo Horizonte, Minas Gerais, 1993 a 1996. Cad Saude Publica. 2000;16:213-23.

5. Oliveira IC, Valencia EF, Costa FG, Dias EP. A epidemiologia do acidente escorpiônico no estado da Paraíba registro dos casos atendidos no Hospital Universitário Lauro Wanderly - UFPB. CCS. 1994;13:75-9.

6. Cruz EF, Yassuda CR, Jim J, Barraviera B. Programa de controle de surto de escorpião Tityus Serrulatus, Lutz e Mello 1922, no Município de Aparecida, SP (scorpiones, Buthidae). Rev Soc Bras Med Trop. 1995;28:123-8.

7. Dorce VA, Sandoval MR. Brazilian scorpion venoms: pharmacological aspects. Cienc Cult. 1992;44:187-191.

8. Sofer S. Scorpion envenomation. Intensive Care Med. 1995;21: 626-8.

9. Cupo P, Figueiredo AB, Filho AP, Pintya AO, Tavares Júnior GA, Caligaris $F$, et al. Acute left ventricular dysfunction of severe scorpion envenomation is related to myocardial perfusion disturbance. Int J Cardiol. 2007;116:98-106. Epub 2006 Jul 10. 
10. Bouaziz M, Bahloul M, Hergafi L, Kallel H, Chaari L, Hamida CB, et al. Factors associated with pulmonary edema in severe scorpion sting patients - a multivariate analysis of 428 cases. Clin Toxicol (Phila). 2006;44:293-300.

11. Karnad DR. Haemodynamic patterns in patients with scorpion envenomation. Heart. 1998;79:485-9.

12. Walter FG, Bilden EF, Gibly RL. Envenomations. Crit Care Clin. 1999;15:353-86.

13. Dias MB, Campolina D, Guerra SD, Andrade Filho A. Escorpionismo. In: Andrade Filho A, Campolina D, Dias MB, editores. Toxicologia na prática clínica. v. 1. Belo Horizonte, MG: Folium; 2001. p. 155-66.

14. Sofer S, Cohen R, Shapir Y, Chen L, Colon A, Scharf SM. Scorpion venom leads to gastrointestinal ischemia despite increased oxygen delivery in pigs. Crit Care Med. 1997;25: 834-40.

15. Mazzei de Dàvila CA, Dàvila DF, Donis JH, de Bellabarba GA, Villarreal V, Barboza JS. Sympathetic nervous system activation, antivenin administration and cardiovascular manifestations of scorpion envenomation. Toxicon. 2002;40:1339-46.

16. Amitai $Y$, Mines $Y$, Aker M, Goitein K. Scorpion sting in children. A review of 51 cases. Clin Pediatr (Phila). 1985;24:136-40.

17. Guerra CM, Moreira CL, Campolina D, Filho AA, Ferreira AR, Guerra SD. Escorpionismo moderado e grave em crianças. Rev Med Minas Gerais. 2001;11(Supl 1):23.

18. Bawaskar HS, Bawaskar PH. Prazosin therapy and scorpion envenomation. J Assoc Physicians India. 2000;48:1175-80.

19. Martínez Canzonieri C, Lizarralde de Grosso M, Corronca JA. Nuevos aportes al conocimiento y tratamiento del escorpionismo humano em la província de Tucuman. Rev Med Tucuman. 1999; 5:57-66.
20. Lourenço WR, Cloudsley-Thompson JL, Cuellar O, Von Eichstedt VR, Barraviera B, Knox MB. The evolution of scorpionism in Brazil in recent years. J Venom Anim Toxins. 1996;2:121-34.

21. Ghalim N, El-Hafny B, Sebti F, Heikel J, Lazar N, Moustanir R, et al. Scorpion envenomation and serotherapy in Morocco. Am J Trop Med Hyg. 2000;62:277-83.

22. Rezende NA, Amaral CF, Freire-Maia L. Immunotherapy for scorpion envenoming in Brazil. Toxicon. 1998;36:1507-13.

23. Bahloul M, Chaari A, Khlaf-Bouaziz N, Hergafi L, Ksibi H, Kallel $H$, et al. Gastrointestinal manifestations in severe scorpion envenomation. Gastroenterol Clin Biol. 2005;29:1001-5.

24. Attamo H, Diawara NA, Garba A. Epidemiology of scorpion envenomations in the pediatric service of the Agadez hospital center (Niger) in 1999. Bull Soc Pathol Exot. 2002;95:209-11.

25. Gueron M, Ilia R. Is antivenom the most successful therapy in scorpion victims? Toxicon. 1999;37:1655-7.

26. Foëx B, Wallis L. Best evidence topic report. Scorpion envenomation: does antivenom reduce serum venom concentrations? Emerg Med J. 2005;22:195-7.

27. Bentur $Y$, Taitelman $U$, Aloufy A. Evaluation of scorpion stings: the poison center perspective. Vet Hum Toxicol. 2003;45: 108-11.

Correspondence:

Cláudia de Moura Nunes Guerra

Hospital João XXIII

Av. Professor Alfredo Balena, 400

CEP 30130-100 - Belo Horizonte, MG - Brazil

Tel.: + 55 (31) 3239.9255

E-mail: claudiamguerra@oi.com.br 